\title{
Next generation technology for learning practical skills online
}

\author{
Elise Crawford, Frank Bogna, Aldo Raineri and Ryan L. Kift \\ Central Queensland University
}

\begin{abstract}
This paper presents a rationale and research approach for a pilot study that examines next generation solutions for enhancing online learning of practical skills required of Occupational Health and Safety (OHS) university students. The study explores instructional technology that has been designed through a constructivist lens. Open source interactive capability and immersive experiences are created using static and 360-degree panoramic photography to encourage greater engagement with the learning resources and to enhance practical skill development at distance. This design research pilot is founded on pedagogy before technology principles and follows the pedagogical model of the cognitive apprenticeship. Survey data, and learning analytics from the University Learning Management System will be interrogated to appraise the education outcomes using the Kirkpatrick Training Evaluation Framework. Expected benefits include improved engagement with learning resources, improved overall OHS skill development, and greater accessibility to workplaces without personal concerns for health and safety.
\end{abstract}

Keywords: 360 Visualisation, Interactive instructional technology, Virtual tours, Higher education

A common approach to ensure occupational health and safety (OHS) courses remain industry relevant, is to embed real world learning opportunities into the curriculum. This often involves worksite visits to apply and hone practical skills. In the process students develop technical competencies for the developing OHS practitioner that in turn requires access to real workplace environments where hazards and associated risks are managed in real time using systems, procedures and interactions between workers. For OHS students, the opportunity to be physically at a worksite allows them to see how work is done, rather than imagined, within the constraints of that workplace. Another onsite advantage for OHS students is the opportunity to explore health and safety risks in sensory rich environments. Access to workplaces allows students to contextualise their learning and helps to prepare them for professional employment (Berman, 2008). This onsite approach has a history of learning success (Reeves, Herrington \& Oliver, 2002). However, accelerated adoption of new technology is dramatically changing the nature or work.

Automation, artificial intelligence, internet of things and system integration is seeing fewer workers in the field and greater concerns for safety in these work environments. Increasingly, workplaces are tightening rules around site access, with some companies preventing all access to visitors on site over concerns for worker and visitor health and safety (Macdonald-Smith, 2020). These restrictions further challenge the continuance of equitable work-based opportunities for students. Universities are also concerned about student safety during work-related activities, and agree student safety is paramount (Quang, Pedro \& Park, 2015). Conversely, changes in the working landscape which is creating bigger business is also seeing the emergence of a gig economy, where the individual's work is less predictable and based on demand (World Economic Forum, 2018). Both scenarios are leading to reduced accessibility to suitable workplaces for occupational health and safety (OHS) students undertaking higher education studies. The ability to secure enough organisations in a single location who are willing to host OHS students while at a residential school is increasingly problematic, even when student safety is managed appropriately while onsite. This is particularly concerning, as the OHS profession is well placed to ensure new technologies are introduced into the workplace safely, for which higher education in OHS can play a significant role. However, the reduction of real work experiences may reduce their graduate readiness, a criticism that has led many universities to adopt Work Integrated Learning opportunities as a strategy for promoting work-ready graduates (Patrick et al., 2008).

Common challenges to work-integrated activities include resourcing associated with increased academic workloads as a result of developing partnerships and maintaining relationships with host organisations. 
Accessibility to suitable organisations is also challenging which can impact equitable student participation in the program (Lawson et al., 2011; Peach et al., 2016). Other researchers have noted that fitting in with industry needs can also be challenging (Choy \& Delahaye, 2011). Nevertheless, it would be a shame to lose these highfidelity opportunities that help to connect students to industry, governments and the community and maintain assessment authenticity. A need exists that can provide OHS students with opportunities to develop practical skills safely and in a manner that aligns with current industry needs. Towards resolution of this issue, this paper presents a rationale and research approach for a pilot study that explores cutting edge learning support using interactive and immersive technology.

\section{Pilot Study Rationale}

Safety education has been criticised for failing to reach practical improvements in industry. This is seen as a significant gap especially for students who gain employment in higher risk industries (Jaeger \& Adair, 2012). Even in industry on-the-job training has been criticised as being expensive, limited and unsafe. Use of virtual reality solutions over the past 20 years has provided the opportunity for students to be immersed in a work environment without the 'do-or-die' consequences of high-risk work environments, such as in the construction industry (Goulding et al., 2012). Virtual reality model-based approaches have been found highly useful for learning what happened, through the re-construction of incidents (Sieberth et al., 2019). However, they have been criticised for not fully reflecting real-world visualisations and lack the clarity of 2D photography. Emergent technology that offers immersive experiences through 360-degree photographic visualisations have been found useful for providing a safe way for students to explore real workplace settings with greater clarity than VR model-based solutions (Pham et al., 2018).

This may open access to otherwise closed worksites for learning purpose related to maintaining skill relevance and task authenticity, two important pedagogical priorities. In industry, visualisations for learning in both 2D and 3D training applications is showing positive learning outcomes (Goulding et al., 2012; Mayer ,2018). This has contributed to safer learning opportunities for high-risk industries by keeping the user remote from frontline operations, in manufacturing and construction (Li et al., 2015), railways (Grogan, 2012) and mining (Bellamy \& Pravica, 2011). Use of 360-degree cameras has also led to improved workplace oversight and interactive working ability (Eiris, Gheisari \& Esmaeili, 2018).

However, utilisation of technology in education continues to be criticised, including the use of 3D visualisations. Therefore, it is important to ensure pedagogy always comes before technology (Cowling \& Birt ,2018). The concern today is that the excitement around new technology and the desire for more economical solutions by education providers can overshadow attention on pedagogy. This is especially concerning today as popularity of digital media is driving a prevailing trend towards 'online anything' including online learning (Mayes, 2018). To establish pedagogy before considering technology can help to ensure technology supports the desired learning outcomes rather than adding to the online teaching repertoire that is criticised for contributing to substandard passive learning (Smith \& Smith, 2014). It is not clear whether technology will ever successfully replace real world experiences and create graduate-ready students. Nevertheless, technology may enhance their learning of skills for the ever-evolving world of work. Successful use of immersive technology has been reported to enhance learning engagement in higher education (Dalgarno et al., 2011). Therefore, exploration of a mix of online and real-world learning solutions that not only enhance engagement but also offer greater connectivity to industry is warranted.

The evaluation of education programs has traditionally comprised the collection of qualitative data on the perceptions of those undertaking the training regarding their own learning (Passmore \& Velez, 2015; Lee-Kelley \& Blackman, 2011). Further consideration for what may be termed 'human resource practice' has not received much attention or application (Passmore \& Velez, 2015, p. 136). If training and education serves to provide competence and application of the knowledge and skills acquired to a workplace setting, then a transformation of these outcomes resulting from the training and education should be measured against the 'particular make-up, operating context and expectations' of the relevant profession (Lester, 2014, p. 285). Therefore, while it may be useful to capture insights from the student's perspective, the Kirkpatrick Training Evaluation Framework offers the opportunity to explore the efficacy of the intervention by considering the transfer of knowledge and skills from the education program to the application of knowledge and skills in real work settings (Passmore \& Velez, 2015). This also allows the novice student to progress like an apprentice to professional practice while value to the organisation's activities may be realised. 


\section{Experimental design}

For this pilot study, design research (Richey \& Klein, 2005) is conducted to create instructional technology that moves away from traditional didactic methods to align more with the pedagogical constructivist paradigm. This learning intervention follows the cognitive apprenticeship model (Collins, Brown \& Newman, 1987) and leverages new technology capability to create instructional technology resources that provide interactive and immersive learning experiences. In this way, instructions for learning move away from the traditional didactic instructional methods. The design research is therefore, founded on pedagogy before technology principles. It is anticipated that enhanced technology support will enhance student engagement with the learning resources and remain pedagogically sound (Beckem \& Watkins, 2012).

The Unit under investigation is a second-year practical unit within the Bachelor of OHS. The residential school component is retained to provide students with collaborative problem-solving opportunities before they are expected to apply learnings on their own for assessment, and thus experience the benefits of learning principles from social constructivism (Bruner, 1973). The principle of attending to pedagogy before technology to solving learning and teaching problems is employed to ensure technology plays a subordinate role that supports the desired pedagogical outcomes (Cowling \& Birt, 2018).

\section{Materials and methods}

The Pedagogy before Technology principles are followed in the following way (Figure 1).

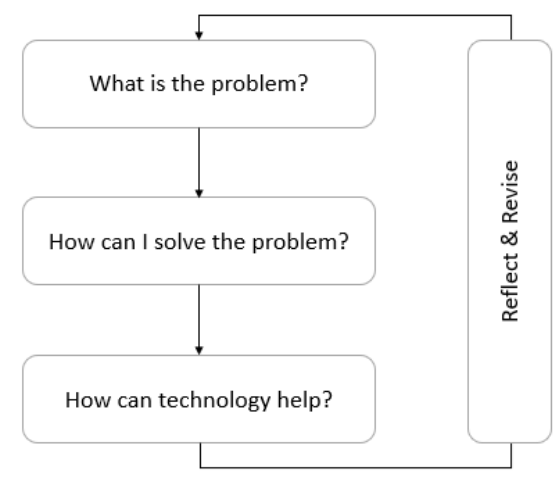

Figure 1: Model for Pedagogy before Technology in a Design-Based Research (DBR) Process Source: Cowling \& Birt (2018, p. 6)

Step one: Identify the problem

The biggest problem observed was that students were not adequately prepared to conduct worksite-based risk assessments and inspections. This was exacerbated by the limited available time for students on worksites. Time on worksites is influenced by the number of available sites, group size limits, and number of enrolled students. Students in larger groups comprised of seven to ten students, have stated that they often miss important information due to operational noise or the necessity to wear hearing protection during worksite tours. Students with little OHS experience have frequently stated that they would have greater opportunity to complete tasks if groups sizes were smaller and if they had more time onsite. Further complicating matters for the 2020 offering is that COVID-19 disruptions and social distancing rules have led to a decision to replace the face-to-face residential with a virtual residential school.

Problem definition statement: Due to COVID-19 social distancing rules OHS students cannot come together to attend a residential school held in Rockhampton Queensland. As the face-to-face residential school is normally the place where skills are demonstrated and conducted under the supervision of teachers, a solution is needed that allows students to conduct authentic practical assessments without the risk of illness, but with the necessary skills to do so without supervision.

Step two: Consider how the problem can be solved

After considering various options, the solution decided was to transfer the onus for finding a suitable workplace host to the students. This would allow students to conduct assessments locally and maintain the authenticity of conducting OHS practical skills on real worksites. This would help to lead students towards independent learning and may even lead to employment opportunities. In cases where this is not feasible, students will be 
offered the opportunity to conduct the assessable activities in their own homes. This allows students to continue to undertake authentic practical tasks that are meaningful to them. Depending on the business agreements, students may be afforded more time on site to conduct activities and those students who conduct assessments and inspections at home may reveal some surprising results which will enhance the relevance of learnings gained.

\section{Step three: Consider how technology can help}

There are several considerations that need to be addressed to support the above solution. To ensure students are adequately prepared to contextualise their learning on their own, instructional technology is developed that provides both interactive and immersive learning experiences. These solutions will help to avoid passive learning and provide a solution to conducting task demonstrations at distance while maintaining task and occupational authenticity. The instructional solutions are created using a variety of sources, such as: 3D and 2D video, static images, vocal overlay and support documentation such as user manuals, Safety Data Sheets, specifications and exemplars of completed worksheets depending on the task.

The interactive content capability allows the student to engage with the provided content, by selecting what video to watch, by reviewing the support material and by learning how to conduct the activity. Immersive technology such as 360-degree photography for virtual tours is used to capture large continuous areas that help to demonstrate more realistically workplace inspections. 360-degree imagery allows students to move about the worksite freely and provides an opportunity for students to explore an industrial work environment without concerns about health and safety. The workplace inspection exemplar also has embedded 2D video recordings of work being performed as well as video discussions with the worker. Furthermore, the workplace inspection exemplar provides immersive experiences of a real workplace and an opportunity to learn about the working conditions as told from the perspective of the worker. Learning is then consolidated while students are together with teaching staff in a virtual setting. Students will be placed in virtual breakout rooms to discuss and to identify health and safety risks and solve problems through various workplace scenarios. The scenarios will be presented to students while at residential school in various media formats (images, documentations, audio, 3D and 2D video-using video conferencing technology. After residential school students conduct various workplace assessments to contextualise their learning. Several University endorsed workplace-student agreement documents were created to support student activities onsite without a university representative present.

Participants in this study are students enrolled in a practical focused course which falls mid-way through their Bachelor of OHS at the authors' institution. About half of the students commence this degree while working in an OHS role, while others are working towards employment in the OHS Profession. Ethics approval to conduct the study is to be sought, and students will be provided information about the study, in the form of a Student Information Sheet. A Survey containing both multiple choice and open-ended questions will be developed to gain insight into student experiences during the term and their perceptions of the learning intervention.

Technology used to create the interactive and immersive experiences include the following: The virtual tours were captured using an Insta360 One R camera on a carbon fibre extension pole mounted to a Sirui Mini Tripod. Two dimensional visualisations were captured using a handheld iPhone 6 Plus camera, and Olympus OMDEM1MkII with an Olympus 12-40mm F2.8 Lens. The interactive solutions were created within H5P Interactive Content and the workplace inspection materials were created within the H5P Virtual Tour capability (https://h5p.org/virtual-tour-360) involving 360-degree images, interactive scene changes, documentation, video messages and close imagery. The solutions will be embedded into the student Learning Management System, Moodle. Virtual meetings during residential school will be facilitated using video conferencing capability via Zoom.

\section{Data analysis}

Data will be thematically analysed and study results will be evaluated against the first three of four levels of the Kirkpatrick's training evaluation framework, as follows (Passmore \& Velez, 2015, p. 137):

- Level 1 includes assessment of training participants' reaction to the training program

- Level 2 is concerned with defining quantitative measures of learning (i.e., skills attained)

- Level 3 addresses the degree to which knowledge and skills are applied to work related contexts

Data comparisons of student grades and demonstration quality of learning outcomes between the 2019- and 2020-year offerings will be compared to capture the learning effects on students. The survey will be used to 
capture insight into student reactions to the educational program and inform recommendations for future course offerings.

\section{Conclusion}

It is anticipated that this learning intervention that models the cognitive apprentice and is supported by new technology will improve student engagement with instructional resources and help to improve their overall skill development. The interactive and immersive experiences are also expected to enhance opportunity to learn from a variety of worksite environments while improving graduate readiness to undertake OHS worksite assessments. Additionally, if this approach is continued, future students will have greater accessibility to OHS education. Universities that adopt this approach will enjoy greater service flexibility that is less resource intense without undermining pedagogy. Most importantly, it is expected that OHS student skill development will improve and thereby better support graduate-readiness through a substitute residential school that allows for work-related assessment components, as reflected in the evaluation of Levels 1, 2 and 3 of Kirkpatrick's Training Evaluation Framework. This may be an important milestone for education providers and students who are not yet employed in OHS roles.

\section{References}

Bellamy, D., \& Pravica, L. (2011). Assessing the impact of driverless haul trucks in Australian surface mining. Resources Policy, 36(2), 149-158. https://doi.org/10.1016/j.resourpol.2010.09.002

Berman, J. (2008). Connecting with industry: bridging the divide. Journal of Higher Education Policy and Management, 30(2), 157-172.

Bruner, J. (1973). Going beyond the information given. New York: Norton.

Choy, S., \& Belahaye, B. (2011). Partnerships between universities and workplaces: some challenges for workintegrated learning. Studies in Continuing Education, 33(2), 157-172.

Collins, A., Brown, J., \& Newman, S. (1988). Cognitive apprenticeship: Teaching the craft of reading, writing and mathematics. Thinking: The Journal of Philosophy for Children, 8(1), 2-10. https://doi.org/10.5840/thinking19888129

Cowling, M., \& Birt, J. (2018). Pedagogy before technology: a design-based research approach to enhancing skills development in Paramedic Science using mixed reality. Information, 9(2), 29. https://doi.org/10.3390/info9020029

Dalgarno, B., Lee, M. J., Carlson, L., Gregory, S., \& Tynan, B. (2011). An Australian and New Zealand scoping study on the use of 3D immersive virtual worlds in higher education. Australasian Journal of Education Technology, 27(1), 1-15.

Eiris, R., Gheisari, M., \& Esmaeili, B. (2018). PARS: Using augmented 360-degree panoramas of reality for construction safety training. International Journal of Environmental Research and Public Health, 15, 24522475.

Goulding, J., Nadim, W., Petridis, P., \& Alshawi, M. (2012). Construction industry offsite production: A virtual reality interactive training environment prototype. Advanced Engineering Informatics, 26(1), 103-116. https://doi.org/10.1016/j.aei.2011.09.004

Grogan, A 2012, 'Driverless trains: It's the automatic choice', Engineering \& Technology, 7(5), pp. 54-57.

Jaeger, M., \& Adair, D. (2012). Construction safety simulations and students' perception of stress. Paper presented at the 40th SEFI Annual Conference 2012 - Engineering Education 2020: Meet the Future, Thessaloniki, Greece.

Lawson, R., Fallshaw, E., Papadopoulos, T., Taylor, T., \& Zanko, M. (2011). Professional learning in the business curriculum: engaging industry, academics and students. Asian Social Science, 7(4), 61-68.

Li, H., Lu, M., Chan, G., \& Skitmore, M. (2015). Proactive training system for safe and efficient precast installation. Automation in Construction, 49, 163-174. https://doi.org/10.1016/j.autcon.2014.10.010

Macdonald-Smith, A. (2020). Essential plants go to extremes to stay online. Financial Review. https://www.afr.com/companies/manufacturing/essential-plants-go-to-extremes-to-stay-online-20200320p54cdn

Mayes, T. (2018). Learning technology and learning relationships. In J. Stephenson (Ed.), Teaching \& learning online: New pedagogies for new technology (eBook ed.). New York: Routledge.

Passmore, J., \& Velez, M. J. (2015). Training Evaluation. In K. Kraiger, J. Passmore, N. Rebelo dos Santos, \& S. Malvezzi (Eds), The Wiley Blackwell Handbook of the Psychology of Training, Development and Performance Improvement, pp. 136-153, Melbourne: John Wiley \& Sons, Ltd.

Patrick, C., Peach, D., Pocknee, C., Webb, F., Fletcher, M., \& Pretto, G. (2008). The WIL (work integrated 
learning) report: A national scoping study (Final Report). Brisbane: Queensland University of Technology. http://eprints.qut.edu.au/44065/

Peach, D., Moore, K., Campbell, M., Winchester-Seeto, T., Ferns, S., Mackaway, J., \& Groundwater, L. (2016). Building institutional capacity to enhance access participation and progression in Work Integrated Learning (WIL). Retrieved from Canberra ACT: Department of Education and Training.

Pham, H. C., Dao, N.-N., Pedro, A., Le, Q. T., Hussain, R., Cho, S., \& Park, C. S. (2018). Virtual field trip for mobile construction safety education using 360-degree panoramic virtual reality. International Journal of Engineering Education, 34(4), 1174-1191.

Quang, T. L., Pedro, A., \& Park, C. S. (2015). A Social Virtual Reality Based Construction Safety Education System for Experiential Learning. Journal of Intelligent \& Robotic Systems, 79(3), 487-506.

Reeves, T. C., Herrington, J., \& Oliver, R. (2002). Authentic activities and online learning. Higher Education Research and Development Society of Australasia, 562-567.

Richey, R., \& Klein, J. (2005). Developmental research methods: Creating knowledge from instructional design and development practice. Journal of Computing in Higher Education, 16, 23-38.

Sieberth, T., Dobay, A., Affolter, R., \& Ebert, L. C. (2019). Applying virtual reality in forensics - a virtual scene walkthrough. Forensic Science, Medicine and Pathology, 15(1), 41-47.

Smith, D., \& Smith, K. (2014). The case for 'passive' learning - the 'silent' community of online learners. European Journal of Open, Distance and e-Learning, 17(2), 86-99.

Crawford, E., Bogna, F., Raineri, A \& Kift, R. L. (2020). Next generation technology for learning practical skills online. In S. Gregory, S. Warburton, \& M. Parkes (Eds.), ASCILITE's First Virtual Conference. Proceedings ASCILITE 2020 in Armidale (pp. 180-185). https://doi.org/10.14742/ascilite2020.0135

Note: All published papers are refereed, having undergone a double-blind peer-review process.

The author(s) assign a Creative Commons by attribution licence enabling others to distribute, remix, tweak, and build upon their work, even commercially, as long as credit is given to the author(s) for the original creation.

(c) Crawford, E., Bogna, F., Raineri, A \& Kift, R. L. 2020 